\title{
Historia y Etnicidad en la Amazonía Peruana: El Caso de los Chayahuita
}

Aldo Fuentes

This article deals with the different social categories of persons, who form the social environment of the Chayahuita, a native people of the Alto Amazonas Province in the Department of Loreto, Peru.

The historical processes that have occured in the region since the 17 th century are brought to bear upon continuity and change in their system of inter-ethnic relations. Of special importance for the definition of Chayahuita identity was their condition as "Christianized Indians" during the period of the Jesuit reductions of Mainas. In spite of the difficult conditions they historically have had and currently continue to endure, the Chayahuita are a case of ethnic identity that, up until now, has been vigorous and viable. 
In diesem Aufsatz werden die unterschiedlichen sozialen Kategorien dargestellt, die für die Chayahuitas, einer Indianergruppe des oberen Amazonas, das soziale Umfeld bilden. Kontinuität und Wandel im System der interethnischen Beziehungen werden mit den historischen Prozessen in Verbindung gebracht, die sich seit dem 17. Jahrhundert in der Region abgespielt haben.

In der Epoche der Reduktionen von Maynas waren die Chayahuitas "christianisierte Indios", was für die Definition ihrer Identität von besonderer Bedeutung gewesen ist.

Trotz der harten Bedingungen, denen sie historisch ausgeselzt waren und sind, stellen sich die Chayahuitas als ein Fall von ethnischer Identität dar, die bis heute lebending ist und auch Zukunft hat.

Dans ce travail, on présente les différentes catégories sociales des personnes qui forment l'environnement social, d'aprés le point de vue des Chayahuita, une population indigène du Haut Amazone.

On établit de liens entre la continuité et le changement dans le système de relations interethniques et les processus historiques qui ont eu lieu dans la région depuis le XVIléme siècle. Pour la définition de l'identité chayahuita, leur condition "d'indiens christianisés" a été très importante pendant l'époque des réductions de Mainas. Malgré les dures conditions qu'ils ont dû et doivent encore affronter, les Chayahuitas sont présentés ici comme un cas didentité ethnique encore fort et viable.

\section{INTRODUCCION}

En este trabajo se presentan las diferentes categorías de personas que forman el medio ambiente social desde la perspectiva de los chayahuita: un pueblo indígena del Alto

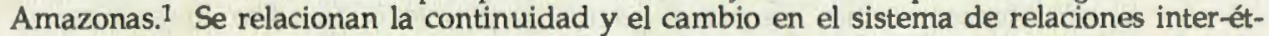
nicas con los procesos históricos que han venido ocurriendo en la región desde el siglo XVII. De particular importancia para la definición de la identidad chayahuita ha sido su condición de "indios cristianizados" durante el periodo de las reducciones de Mainas.

A pesar de las duras condiciones que históricamente han tenido ( $y$ tienen) que enfrentar, los chayahuita son presentados como un caso de identidad étnica hasta ahora vigorosa y viable. Esto podria lievarnos a ser optimistas sobre el futuro del grupo. Pero...

Los chayahuita son actualmente una población de más de diez mil perșonas que ocupan un extenso territorio entre los rios Cahuapanas, Sillai, Paranapuras, Shanusi, y sus afluentes menores. Su habitat es típicamente "inter-riberefo". Aunque esto es una desventaja en términos de recursos de caza y pesca, ha tenido también su lado positivo al desalentar, hasta ahora, una masiva colonización de su territorio. Sin embargo, se sabe que el área ribereña circundante está enfrentando una creciente presión poblacional que, en algún 
momento, podría derivar hacia el territorio de los chayahuita. Es posible que no les quede mucho tiempo para prepararse a enfrentar este reto. Y también para realizar los ajustus necesarios a su modo de subsistencia para hacer frente a la escasez de proteinas y al crecimiento poblacional del propio grupo étnico. Mientras tanto, las migraciontes fuera de su territorio han estado funcionando de "válvula de escape" que todavía permite mantener la "tradicional" cultura y organización social. La pregunta es: ¿por cuánto tiempo?

\section{Antecedentes históricos}

Los Chayahuita han tenido una larga historia de contacto mas o menos permanente: primero con la sociedad colonial y luego con los frentes de expansión de la sociedad peruana. El carácter e intensidad de dichos contactos, sin embargo, no han sido los mismos a lo largo de la historia; dependiendo, en cada época, de la dinámica de la economía política en lo que, en términos generales, se conoce como la región del Alto Amazonas. Si bien la tendencia general ha sido de una cada vez mayor articulación con la sociedad nacional, ésta no ha seguido una línea ascendente: en ocasiones, a periódos de intensos contactos han seguido otros de una relativa mayor autonomía. Esto, como se verá, ha tenido una incidencia en la identidad étnica nativa: tanto en las marcas "diacríticas" en que se manifiesta como en los focos en que se concentran el conjunto devalores y significados que constituyen su contenido. ${ }^{2}$

El avance español sobre la región de Mainas significó, en los primeros años, una demanda forzada de mano de obra indígena, principalmente para el servicio doméstico y el trabajo agrícola en los fundos de los vecinos de Moyobamba. ${ }^{3}$

Durante los primeros años de contacto la drástica reducción poblacional ocasionada por las epidemias, los traslados forzosos de población o la huida hacia las zonas inaccesibles, tuvo un efecto desestructurador sobre la sociedad indigena. Las "parcialidades" (¿familias extensas?, ¿clanes?, ¿malocas?, ¿mitades?) que algunos informes reconocen, se ven obligadas a mudarse de ubicación o a amalgamarse entre sí; otras desaparecen, etc. Tal es el caso, por ejemplo de los Jebero, que en los primeros informes aparecen como sustituidos en varias de estas "parcialidades", pero que luego serán vistos como un conglomerado maso menos homogéneo vis a vis otros grupos étnicos y en sus relaciones con los españoles (Figueroa 1904). También se produjo un deterioro y quiebra de antiguas redes de intercambio y relación como las que unían a los Cahuapanas con los indígenas de la ciudad de Moyobamba y Lamas (Chantre 1901, p. 300).

Desde 1638 los jesuitas partirán en busca de esta población refugiada en las cabeceras de los ríos y con su organización profundamente alterada, e intentarán, con diversos grados de éxito, reproducir su modelo de sistema misional.

La base del nuevo sistema organizativo era el pueblo-reducción. En éste, bajo la autoridad central del misionero, se constituyó un sistema socio-político nativo con sus propias autoridades civiles, eclesiásticas y militares: gobernador, alcaldes, regidores, oficiales de milicias y fiscales. La necesidad de medios "didácticos" atrayentes para llevar adelante la evangelización condujo a los misioneros a promover la participación en el ciclo de fiestas religiosas católicas (Navidad, Semana Santa, Corpus), a través de un sistema de cargos semejante al que, por la misma época, se difundía en el área andina. 
Allí donde los misioneros lograron alguna estabilidad -como entre los chayahuita- el sistema de autoridades indígenas y el ciclo de fiestas católicas dejaron una huella profunda y pasaron a incorporarse como "marcas" de una identidad étnica indigena. Es sólo en los últímos años que se han venido produciendo cambios en un sistema que, desde la salida de los misioneros, permaneció fundamentalmente inalterado por mas de doscientos años.

Los jesuitas encontraron varios niveles de organización preexistentes: en primer lugar los grupos locales o grupos domésticos, generalmente viviendo bajo un mismo techo o en estrecha proximidad; lucgo lo que ellos llaman "parcialidades" y cuyo carácter no definun explícitamente pero que es posible suponer que se constituían por la asociación de varios grupos locales unidos por lazos de parentesco y matrimonio; en un nivel superior estaban las "naciones" con las que hacían referencia a un criterio territorial (varias parcialidades contiguas habitando a lo largo de un río o quebrada), e idiomático (generalmente habia una correspondencia entre una "nación" y una lengua).

Para el caso que nos ocupa, los jesuitas distinguieron tres "naciones": los Chayavitas, los Cahuapanas y los Paranapuras, al parecer cada una con su propio idioma pero con intercomprensibilidad mutua. Además establecieron que el Jebero era la lengua "matriz" de las otras tres y tenía un cierto grado de intercomprensión con ellas. En mi investigación he encontrado que en la actualidad hay un sólo idioma: el Chayahuita, con tres variantes dialectales que corresponden a la población de los ríos Sillai, Cahuapanas y Paranapuras (con sus afluentes). Si bien los nativos reconocen peculiaridades idiosincráticas y de habla para los miembros de los grupos respectivos, se reconocen todos a sí mismos como una misma gente (piyapi) por oposición a otras categorías (vel más adelante). Aunque he encontrado un cierto número de palabras cognadas entre el Chayahuita y el Jebero (usando el vocabulario de Tessman para éste último), en la actualidad ambas lenguas no son mutuamente comprensibles.

Yo me inclino a creer que los jesuitas exageraron un poco al ubicar el Chayahuita, Cahuapana y Paranapura como tres lenguas diferentes (lo que estaria en contradicción con sus propios informes sobre la intercomprensión mutua entre ellas) pero, por otra parte, creo que como resultado de una mayor frecuencia de contactos y por encontrarse varios grupos reducidos en un mismo pueblo, ha habido una cierta homogeneización entre las variantes dialectales del idioma.

No es claro, aparte del hecho de ocupar territorios diferentes, si entre los tres grupos mencionados había, en el tiempo de los jesuitas, algún tipo de "fronteras" étnicas, como parece sugerir el empleo del término "naciones". Actualmente no se distinguen tales fronteras aunque, por cierto, los informantes dan un conjunto de peculiaridades para cada grupo: como en el vestido, la entonación, el carácter de las personas etc., que hacen fácilmente reconocible la procedencia de una persona.

Si bien las referencias a las "naciones" son abundantes en la bibliografía y en los censos de la época, las otras referencias - al grupo local v a la "parcialidad"- no son muy claras. Lo que no debe inducirnos a creer que estos niveles de organización hubiesen perdido todo significado a los ojos de los nativos. Su "invisibilidad" se debió más bien a que no eran relevantes en términos del "manejo" que los representantes de la sociedad mayor (misioneros y otros) tenían de los nativos.

El destino de estas parcialidades no ha sido uniforme en todos los casos de los que 
lungo alguna información. En Jeberos, y también en Santa María de Cahuapanas, parece que finalmente se diluyeron para dar paso a una identidad mas general. En estos pueblos, por otra parte, cuajó una organización en "mitades" que, al parecer, correspondía a diferontes grupos étnicos o "naciones", reducidos en un mismo pueblo antes que a segmentos al Interior de una etnia. La posterior difusión del Quechua (a fines de facilitar la evangelianción) eventualmente condujo a una mayor homogeneización, pero, de alguna manera se duben de haber mantenido las fronteras entre las "mitades" pues Raimondi encontraba una organización de dos barrios (de "arriba" y de "abajo") en Jeberos, todavía a mediados del siglo pasado. Yo mismo he encontrado en Santa Maria de Cahuapanas una organizaılon similar ("arribinos" y "abajinos", teniendo por eje central a la iglesia del pueblo).

Los ciento treinta años de misiones jesuitas tuvieron un efecto adicional sobre las relaciones inter-étnicas en la región del Alto Amazonas al establecer la dicotomía entre indios cristianos (ie., aquellos que por diversos motivos habían aceptado vivir en los pueblos-reducciones, realizando ajustes en su organización social y modo de subsistencia) y aquellos que rechazaron someterse, llamados también infieles. Un ejemplo de esta última categoría lo constituyen los aguaruna, quienes, no sólo se mantuvieron alejados del sistema misional sino que en diversas oportunidades se declararon en abierta hostilidad.

Debemos destacar, finalmente, que el hecho de no haber podido nunca contar con suficiente personal misionero, obligó a los jesuitas a una forma "indirecta" de evangelización: a través de algunos indígenas a los que se capacitaba para ello. Esto, aunado al "gobiemo indirecto" de las misiones a través de las autoridades nativas, creemos que posibilitó un cierto grado de yuxtaposición y reinterpretación de los elementos culturales que les eran impuestos, lo que, a su vez, pudo favorecer la persistencia de una identidad étnica.

Si la expulsión de los jesuitas en 1767 respondía a la necesidad de un mayor control directo de los territorios de Mainas por parte del poder central, el resultado contradijo ampliamente las espectativas. Faltos de la motivación y la disciplina de los jesuitas, los sacerdotes seculares que los sucedieron fueron incapaces de asegurar un mínimo de funcionamiento del sistema de las reducciones. Los pueblos menos consolidados se desintegraron rápidamente; al dispersarse, los indigenas retomaron su modo de vida tradicional. Los pueblos más antiguos, entre los que se cuentan Chayahuitas, Santa María de Cahuapanas y Jeberos, vieron reducirse su población pero no llegaron a desaparecer del todo. De esta época probablemente data el patrón contemporáneo de asentamiento de los chayahuita quienes permanecen parte del afio dispersos en sus "tambos", reuniéndose en el pueblo con ocasión de las grandes festividades religiosas como Navidad y Pascua.

Roto el dique de las misiones, se inició la expansión de la frontera económica en la región del Alto Amazonas. La economía extractiva se sustentaba en la fuerza de trabajo indígena. Dentro de ésta, la de los "indios cristianizados" - los chayahuita entre ellos - resultó ser la mas fácilmente accesible. Contribuyeron a ello una serie de factores: su asentamiento en pueblos ubicados cerca de la ruta obligada de tráfico; su dependencia, para su subsistencia, de objetos que no fabricaban ellos mismos como herramientas, ropa, etc; la interiorización - finalmente- de las relaciones de dominación a que habían estado expuestos en el periodo anterior. Los informes son unánimes en atestiguar el carácter "dócil" de estos indígenas, que contrastaba con la "arrogancia" y la "belicosidad" de los no reducidos, como los aguaruna, quienes en repetidas oportunidades llegarian a asolar los asentamientos de colonos: Santiago, Barranca, Borja. Los chayahuita en este período actuaban de "cargueros"'" sustentando asi el flujo comercial que articulaba la selva baja con la región de San Martín y con la costa. Aún ahora, en la tradición oral, los nativos 
recuerdan los duros viajes que se veían obligados a hacer hasta Moyobamba, a través de desfiladeros y montes, para cumplir con sus obligaciones de cargueros.

El exceso de demanda por el trabajo indígena motivó en algunos casos, como el de Balsapuerto, una despoblación masiva por emigración a las partes bajas (Amazonas, Marañón ). Huyendo de las presiones de las autoridades que les obligaban a una prestación cuasi gratuita de trabajo, o cayendo en manos de patrones que los trasladaban fuera de sus pueblos; de ésta época (fines del siglo XVlll a mediados del XIX) datan las primeras migraciones que hemos podido rastrear de chayahuitas fuera de sus territorios tradicionales. Es posible que esto explique la presencia de apellidos chayahuita que hemos encontrado en sitios tan alejados como el Amazonas, cerca a lquitos. ${ }^{4}$

El boom cauchero no fué sino la agudización y culminación de un ciclo de expansión económica sobre la región. Ya desde el inicio de la navegación a vapor en 1856-57 se había acelerado el movimiento comercial. Como resultado, algunos puntos estratégicos fueron ganando importancia: Nauta, Yurimaguas, Iquitos, en tanto que los antiguos pucblos de la "misión alta" (como Chayahuitas, Cahuapanas y otros) languidecian. Con la nevcgación a vapor está también asociado cl surgimiento de haciendas y la creciente ocupación de las riberas de los ríos por parte de población mestiza, proveniente en su mayoría del departamento de San Martín.

El siglo XX se caracteriza por un incremento de la ocupación del área por parte de población no nativa. Algunos descienden de los antiguos caucheros, otros fueron llegando en los sucesivos "booms" extractivos: barbasco, shiringa, leche caspi, madera, petróleo. La ocupación mestiza, con todo, ha sido mayor en el área ribereña (Huallaga, Marañón) y en las proximidades de ciudades como Yurimaguas. El área inter-ribercha y los ríos menores como el Cahuapanas y el Sillai -donde viven los chayahuita - mantiene una mayor proporción de población nativa.

Hasta hace pocos afios la mayoría de los chayahuita estuvieron viviendo bajo dependencia de patrones. Así, los nombres de algunas de las actuales comunidades tienen su orígen en ex-fundos. La decadencia del sistema de haciendas motivada por factores ligados a la dinámica económica nacional ha sido tratada por Caballero (1981) para el área andina y Stocks (1981: 89-92) para el área del bajo Huallaga: el proceso parece haber sido paralelo en la sierra y selva. La promulgación de la Ley de Comunidades Nativas, la acción de SINAMOS y de algunos misioneros parecen haber acelerado la liquidación de una dependencia directa de patrones que, sin embargo, ya se veía venir. El "orden gamonal" (Caballero, op cit) sin embargo, persiste todavía. ${ }^{5}$ La dependencia y subordinación se dan ahora a través de las relaciones de comercialización (regatones, comerciantes-expatrones) y el monopolio del poder político e información por parte de un reducido grupo de personas.

En todo este tiempo (1940 en adelante) se ha ido definiendo una nueva estructura económica regional: llegándose a una articulación con el mercado de las comunidades mas alejadas. El crecimiento relativo de ciudades como Yurimaguas se debe a esta "revolución comercial" (Webb 1977).6 Aquí, y en otros centros menores como San Lorenzo, se concentran los servicios y el comercio. El área rural se mantiene predominantemente campesina y nativa, la agricultura de subsistencia se combina con cultivos destinados al mercado. 7

A mediados de la década del 40 el ILV inició èl estudio del idioma y proselitismo 
religioso entre los chayahuita. No será hasta los años 70 , sin embargo, que se inicia la creación masiva de escuelas bilingües y la concentración de población en Comunidades Nativas. En la actualidad un alto porcentaje de comunidades han abrazado (por lo menos formalmente) el protestantismo en sus diferentes sectas. Las comunidades mas tradicionales son aquellas que todavía practican una forma de catolicismo "folk" que data del tiempo de las misiones de Mainas (Pueblo Chayahuita es una comunidad de este tipo). No obstante, como se verá, la identidad étnica chayahuita es todavía común a ambos tipos de comunidades, mas allá de los faccionalismos religiosos.

\section{Categorías étnicas e interacción}

Para referirse a si mismo los chayahuita emplean los términos campo piyapi 'nuestra gente', ó, simplemente, piyapi 'gente'. El autoreconocimiento implica una serie de características, aparte -obviamente- del hecho de hablar un mismo idioma: 1) participación de un modo de subsistencia adaptado al trabajo agrícola y la obtención de recursos de caza en el bosque $y$, en menor medida, de pesca en los ríos pequeños que cruzan su territorio. Este modo de subsistencia implica una división del trabajo de acuerdo al sexo y un conjunto de valoraciones asociadas. 2) Participación en un sistema social en el que tienen especial importancia la práctica de la residencia matrilocal, y un sistema de parentesco bilateral, actualizado con ocasión de las contraprestaciones recíprocas de ayuda en trabajo para las diferentes tareas que demanda su modo de producción. 3) Participación de una etiqueta típica de hospitalidad en la que juega un rol central el brindar masato siguiendo pautas específicas para la situación. 4) Participación en el sistema socio-político de un pueblo (ninano) con su sistema de autoridades tradicionales, participación en los trabajos comunales, etc. 5) Participación en un sistema interpretativo y ritual propio en el que tienen particular importancia algunos ritos de pasaje (ritual femenino de pubertad, ritos funerarios), los "rituales de aflicción" (shamanismo) y el sistema de fiestas católicas tradicionales (Navidad, Pascua, Corpus).

Como se ve, la identidad étnica, en una situación tradicional como la de los chayahuita, abarca prácticamente todas las esferas de la vida y se actualiza "públicamente" y en contextos "privados" por igual. Se ve también que, a excepción de la participación en el ciclo de fiestas católicas y (en menor medida) en los ritos shamanísticos, los demás elementos que definen la identidad étnica son comunes tanto a las comunidades "católicas" como a las "evangelistas".

Al interior del grupo de "nuestra gente" así definido, los chayahuita distinguen por lo menos tres subcategorías, en base a los criterios de territorialidad y variantes dialectales de una misma lengua:

Capanai: Los habitantes de la cuenca del Cahuapanas

Namëi: $\quad$ Los habitantes del Sillai y Alto Paranapuras.

Yamarai: Los habitantes del Paranapuras medio y afluentes, como el Yanayaco/ y Cachiyaco.

No se establecen fronteras étnicas entre estos tres grupos, si por ellas se entiende, siguiendo a Barth aquellas en las que se "clasifica a una persona de acuerdo con su identidad básica y más general, supuestamente determinada por su orígen y formación" (Barth, F, op cit. p15). Con todo, aparte de los elementos "idiosincráticos" mencionados 
anteriormente, se nota una menor frecuencia estadística de inter-matrimonios entre los tres grupos, sin llegar a una endogamia total. Normativamente no hay prohibiciones en tal sentido. Las historias de contacto son también algo distintas pues tanto los "cahuapaninos" como los "cachiyaquinos" (como también se los conoce) han estado en mayor contacto que los otros. Con todo, si, nuevamente siguiendo a Barth, tomamos en cuenta para adscribir la identidad étnica no algunos rasgos culturales tomados arbitrariamente por nosotros (como la mayor frecuencia de vestimenta occidental o dominio del castellano en un grupo con relación a otro), sino las categorias de adscripción usadas por los propios actores, entonces, es justificado incluir a los tres grupos como participantes de una misma identidad étnica.

Conceptualmente y cuando interactúan con otros grupos étnicos, los chayahuita tienden a enfatizar determinadas características culturales como distintivas. Estas no son las mismas en cada caso: los rasgos que se enfatizan frente a un grupo no necesariamente coinciden con los que se emplean como diacríticos en la interacción con otro. El siguiente diagrama muestra las diferentes categorias de personas desde la perspectiva de los chayahuita.

Como se ha visto, la presencia significativa de mestizos en la región data de mediados del siglo pasado y se incrementa considerablemente en las últimas décadas.

En una primera etapa las relaciones con este sector eran casi exclusivamente a través de los patrones que explotaban el trabajo de los chayahuita para extraer los productos del bosque, o como cargueros, retribuyéndoles en especies (ropa, cartuchos, machetes) en un intercambio desigual. El sistema de endeudamiento de por vida que obligaba al nativo a trabajar para el patrón es suficientemente conocido por ser de difusión generalizada en la amazonia, por lo que no ahondaremos mas en él. Lo que nos interesa constatar es que el carácter de las relaciones que se establecieron (dominación y aún coerción física -penas de azotes o calabozo implantadas por el patrón para los que no cumplían con sus - "dudas"-) ha marcado la forma como los nativos perciben a los mestizos, aún después de liquidado el sistema patronal.

Al retirarse los patrones de la mayoría de las comunidades chayahuita y al diversificarse la economía regional, las relaciones con el estrato mestizo se han hecho algo mas impersonales. Los chayahuita que bajan a Yurimaguas tienen la alternativa de vender su producción a las agencias gubernamentales que tienen a su cargo la comercialización de algunos productos agrícolas. Aunque todavía dependen del establecimiento de lazos de clientelismo para obtener alojamiento o conseguir pequeños préstamos, la interacción con los mestizos se circunscribe mayormente a las transacciones en la esfera del "mercado".

Este es un campo en el que los nativos no tiener el menor control tanto en los precios que reciben por sus productos como en los de los artículos que desean adquirir. 8 No obstante, tengo la impresión de que las expediciones comerciales a Yurimaguas y San Lorenzo son para los chayahuita "viajes de placer" tanto o mas que "viajes de negocios". Significan un cambio agradable frente a la rutina de la aldea y una oportunidad de admirar todas las maravillas de la sociedad de consumo.

Aunque la imposibilidad de adquirir la mayor parte de esas maravillas crea un cierto sentimiento de frustración, los chayahuita enfatizan algunos valores propios que, a sus ojos, los ponen en una situación de superioridad frente a los mestizos. Frecuentemen- 
te contrastan su propio sistema de reciprocidad, y la posibilidad de conseguir lo que necesitan para su subsistencia a partir de su entorno natural, con la necesidad que tienen los mestizos de ponerle un precio en dinero a todas las cosas. Se admiran, por ejemplo, que en Yurimaguas hasta la leña y los productos silvestres del bosque tengan un precio en dinero: algo impensable dentro de su propia cultura. Dado que las actividades destinadas a la obtención de dinero (como el cultivo del arroz) está entre las mas pesadas y tediosas (si se las compara con lo que hay de excitante exploración en una expedición de caza o de pesca), están enfatizando de este modo su propio sentimiento de independencia y libertad que, de alguna manera, se percibe amenazado por la sujocción a una economía de mercado.

Otro aspecto de su cultura que los chayahuita enfatizan como contrastante con la de los mestizos es su habilidad para llevar adelante sus actividades de subsistencia, y las valoraciones positivas que están asociadas con ellas: los hombres como cazadores, las mujeres como abastecedoras de productos de la chacra y artesanas. La complementariedad que implica la división tradicional del trabajo está entre las razones por las que los chayahuita se oponen decididamente a los matrimonios inter-étnicos. A diferencia de otros grupos nativos fuertemente desestructurados, los chayahuita no consideran que un matrimonio con un mestizo (o mestiza) sea un ascenso en la escala social 10 .

Por su parte, los mestizos tienen sus propios estereotipos de lo que son los chayahuita ("haraganes", "desidiosos", "cerrados", "ignorantes" etc). emplean peyorativamente el término "balsacho" (de Balsapuertino) para referirse a todo en general, aunque no vengan de Balsapuerto. Algunos de estos estereotipos se han filtrado en la autovaloración de los propios nativos: principalmente el que hace referencia a su poco conocimiento del castellano y su analfabetismo. Esto se explica por la desventaja que supone en las transacciones comerciales y de ahí el entusiasmo con que ha sido recibida la creación reciente de escuelas.

La categoría de "aucas" hace referencia a los nativos que históricamente se mantuvieron alejados de las misiones de Mainas. Entre estos, los aguaruna han tenido un lugar -importante por el tipo de relaciones que han tenido con los chayahuita.

La expansión aguaruna sobre el territorio tradicional de los chayahuita puede fecharse entre la última década del siglo pasado y el primer cuarto de siglo presente. En 1888 Visalot había encontrado un grupo de aguarunas en las cabeceras del Cahuapanas, "armados de lanzas, escopetas y rifles de precisión". La tradición oral chayahuita registra repetidas incursiones a los pueblos de Chayahuitas y Santa María de Cahuapanas. Como resultado de estas hubo un movimiento de dispersión y traslado a ubicaciones mas seguras. En 1919 los aguaruna habían incursionado hasta un punto tan lejano hacia el este como Soledad, un fundo en el límite entre el curso medio y superior del Paranapuras. Tessman (1930) y Corera (1959) registran un ataque de importancia hacia 1925 como resultado del cual se dispersó totalmente la población de Cahuapanas y el Pueblo de Chayahuitas se trasladó a lo que es su actual ubicación. Parte de la población de este último emigró hasta sitios tan alejados como Balsapuerto, el Shanusi. También de esta época data el repoblamiento del Sillai. Cuando visitó la región hacia 1926 el Pasionista, P. Corera encontró a los de Pueblo Chayahuita en un estado de aguda tensión: todos los asistentes a la fiesta de San Antonio estaban armados y parecían en constante alerta. Cuando Corera quiso trasladarse a Santa María se negaron a acompanarle - por temor a una emboscada aguaruna - por un camino que en 1842 el Obispo Arriaga había recorrido acompañado por las mujeres del pueblo como cargueros. 
Lo mágico-sobrenatural ha estado siempre presente en los conflictos entre ambos grupos: después de haberse llevado los ornamentos de la iglesia de Santa María, los aguaruna se vieron obligados a devolverlos pues atribuyeron varias muertes seguidas - por enfermedades y mordeduras de serpientes-al poder hostil de los objetos sagrados de sus enemigos.

Si los chayahuita son, para los aguaruna, sospechosos de ser brujos en potencia, estos últimos (los aguaruna), a su vez, son considerados como "salvajes" o gente fuera del dominio de la cultura. Si bien oposiciones de este tipo se encuentran en muchos grupos amazónicos, en este caso se ha visto reforzada por la dicotomía entre "indios cristianos" e "infieles" que cristalizó en la época de los jesuitas.

Si esta era la situación a comienzos del presente siglo, la presencia de los misioneros, y luego las mayores relaciones con el mundo de fuera han contribuido a pacificar la región. Aunque ya no se realizan correrías como la que destruyó Pueblo Chayahuita, las relaciones inter-étnicas entre ambos grupos mantienen siempre una carga de tensión. La muerte de varios shamanes chayahuita en los últimos diez años (en una verdadera cacería de brujos) es atribuida generalmente a un grupo de aguarunas estabiecidos por las cabeceras del Sillai. Es conocido el lugar que ocupa la brujería en el sistema interpretativo aguaruna, lo que puede explicar esta situación.

Hemos visto que el término huayra hace referencia al sector mestizo de la población. Este, sin embargo, es un término genérico que, dependiendo de las circunstancias, puede recibir dos especificaciones. Cuando se trata de la clase dominante local y regional (autoridades, burocracia estatal, patrones, comerciantes, etc), los chayahuita pueden emplear alternativamente el término wiracocha. Cuando hacen referencia al sector de campesinos pobres ribereños se usa el término pëwènantë.

El contenido de este término es un tanto ambiguo. En ocasiones se emplea como sinónimo: huaya miachin que podría ser traducido como "mestizo a medias" ó "casi mestizo", lo que revela la conciencia de que propiamente no se trata de mestizos en el sentido lato del término (i.e. wiracochas)

Esto tiẹne su justificación objetiva. Por su modo de subsistencia, los pèzuènantë no se diferencian radicalmente de los chayahuita ( $\mathrm{y}$ también de otros nativos). Las diferencias, en todo caso, son de grado: la agricultura para el mercado está mas desarrollada, la caza es menos frecuente - pero en compensación hay mas pesca- etc ${ }^{12}$. También social y culturalmente hay algunas similitudes: aunque la familia nuclear pareciera ser mas frecuente entre los pëwënantè, los lazos de parentesco no han perdido del todo su importancia. Del mismo modo, en su visión del mundo están presentes - bajo nombres y con características algo distintas - algunos seres espirituales y creencias que un chayahuita bien podría reconocer como emparentados con los suyos propios.

Hay, con todo, algunas diferencias, que son precisamente las que permiten ubicarlos como una categoría distinta. En primer lugar está el idioma: los péwënantë se supone que son básicamente monolingües en castellano (veremos mas adelante que no siempre es así) y, aunque en términos de rasgos aislados puedan tener elementos comunes con los chayahuita, su orientación general básica - me parece- es hacia la sociedad mayor ${ }^{13}$. Finalmente, aunque los hemos identificado como campesinos ribereños, una parte de esta población está migrando a las ciudades, donde pasan a constituir el creciente número de pueblos jóvenes, ó, aún si no migran definitivamente, tienen una cada vez mas creciente orien- 
tación urbana en sus actividades productivas y espectativas.

Si bien como categoría étnica los pëuënantë son considerados como claramente distintos de los chayahuita, en la práctica encontré que en algunos casos, personas chayahuita parecían ser identificados como péwènantë como correlato a un proceso migratorio que los había llevado a establecerse fuera del territorio étnico. A veces se emplea también, referido a ellos, el término shaawí miachin ' chayahuitas a medias'.14

\section{"Osmosis" de personal y factores ligados al cambio de identidad}

La interacción de un conjunto de factores históricos, ecológicos y poblacionales ha conducido, entre los chayahuita, a la situación actual, en la que una parte de su población se ha venido trasladando fuera del territorio étnico para establecerse en caserios cercanos a los ríos mayores o en centros poblados como San Lorenzo y Yurimaguas. 15

Entre los factores históricos se cuentan el secular proceso de extracción de excedentes - bajo diversas modalidades - a que ha estado expuesta la población nativa. Esto, aunado a la depredación de los recursos naturales ha conducido a un estado de pobreza generalizada.

Por su ecología los chayahuita pueden ser considerados como un pueblo "inter-riberefo" (Lathrap 1970). Esto de por sí representaba un handicap en lo que a acceso a recursos se refiere, ya incluso antes de que la articulación con la sociedad colonial condujera a la extracción de trabajo y recursos que se ha mencionado en el párrafo anterior. La distancia a los mercados urbanos es otro factor que ha contribuido a mantener una situación de desventaja de los chayahuita, aún ahora cuando se han abierto las posibilidades de cosechas comerciales con una demanda y precios relativamente asegurados, como es el caso del arroz o el maiz.

El crecimiento poblacional sostenido que ha venido soportando el área se ha convertido, también, en uno de los factores que, en combinación con los anteriores ha conducido a empujar la migración de algunos nativos. 16

Hemos delincado, tentativamente, algunos tipos de estrategias seguidas por los migrantes chayahuita. Cada una de ellas es la respuesta a un conjunto de condicionamientos específicos $y$, a su vez, tiene implicaciones particulares en lo que se refiere a la identidad étnica.

a. "Endeudamiento".- Algunas familias chayahuita han establecido lazos de clientelismo con patrones en el área ribereña del Marañón. Esto les permite, a cambio de su trabajo en tareas como la extracción de madera o el cuidado de los pastizales del patrón, el acceso a una porción de terreno donde, de alguna manera, reproducen sus patrones de subsistencia.

Dadas las dificultades para conseguir acceso a la tierra en las áreas ribereñas densamente pobladas (a lo que se añadiría la concentración de la propiedad de la tierra en esta parte), ésta puede ser, en ocasiones, la única manera disponible de subsistir si, por diversos motivos, (como los conflictos derivados de acusaciones graves de brujería) no se 
desea volver al territorio étnico. A lo que se añadiría la falta de un conocimiento suficiente del castellano, lo que dificulta la obtención de algún emples urbano u otra fuente alternativa de subsistencia. Un ejemplo de este tipo de estrategia lo hemos visto en el fundo de "Venezuela" cercano al pueblo de San Lorenzo, en el Marañón.

Este tipo de estrategia involucra a familias extensas completas que, en ocasiones, protagonizan verdaderos y literales éxodos, llevando consigo sus animales, semillas, esquejes de yuca y plantones de plátano etc., expresando así el carácter al parecer definitivo de su emigración.

El aislamiento frente al mundo exterior, en el que los únicos contactos se hacen por mediación del patrón, pueden posibilitar en estos casos la formación de verdaderos "enclaves" nativos en medio de una población mestiza mayoritaria. Sería necesario, sin embargo, investigar más, para ver por cuanto tiempo puede mantenerse esta situación pues, al parecer, las posibilidades - aunque limitadas - de dar a los hijos un mínimo de educación formal en el medio urbano (relativamente cercano), o la misma socialización de los hijos en el contexto mestizo, puede llevar, en la siguiente generación, a una asimilación a una categoría de "cholada" de peones rurales viviendo en los sectores periféricos de las ciudades.

b. "Agregación"- Como campesinos, en caserios ribereños independientes. Es un tipo de estrategia que, a diferencia de la anterior, parece estar asociada a migraciones a título individual. Frecuentemente se trata de un segundo paso en nativos que salieron de su tierra enganchados a patrones. La independencia y posterior asentamiento en una aldea riberena pueder estar ligados a matrimonios con mujeres pëwënantë. (También se da el caso inverso: mujeres nativas con hombres pëwünantè).

En este caso, la falta de "foros" donde se pueda expresar públicamente una identidad chayahuita y la no relevancia de ésta para la interacción cotidiana pueden conducir a que quede "latente". No se trata aquí de una asimilación (por lo menos en una primera generación), pues he visto casos de este tipo en los que la identidad vuelve a ser actualizada cuando, por ejemplo, en ocasiones, el migrante regresa de visita - a veces después de muchos años- a su comunidad de origen.

También se puede dar el caso de que la comunidad ribereña a la que el migrante se "agrega" esté formada en parte por gente con antecedentes chayahuita, en cuyo caso hay más probabilidades que la identidad étnica se mantenga, en este contexto, circunscrita a algunas esferas privadas de interacción. Casos de este tipo, conocidos localmente como caseríos de "idiomeros", son frecuentes en el Marafión. Ejemplos: los caseríos de Arco Iris, Cunchiyacu, Florida y otros.

c. Un tercer tipo de estrategia es una variante de la anterior, con la diferencia, en este caso, de que la migración individual desemboca en un centro urbano. Se da aquí dos casos:

1. El migrante adquiere un rol de trabajador indiferenciado, como peón, cargador, o empleada doméstica. Se trataría de otro caso de identidad "latente" como el que se presenta en $b$.

2. El migrante ocupa un "nicho" específico para el que representa una ventaja su pasado tribal. Así, hemos encontrado un nativo que había tomado la ocupación de "mitayero" profesional y abastecía de carne de monte en la ciudad de Yurimaguas. El no resi- 
día permanentemente en su comunidad de origen, por el Paranapuras medio, aunque esporádicamente hacia visitas a sus familiares allí. Tenía una casa propia en Yurimaguas y alternaba su residencia aquí con temporadas en las que se internaba en el bosque por varias semanas para conseguir grandes cantidades de carne que luego vendía a algunos comerciantes mayoristas que se encargaban de su distribución. Este nativo había trabajado anteriormente como motorista. Aunque estaba casado con una mujer mestiza y se desenvolvía con bastante soltura en el medio urbano, no parecía avergonzado de su origen y, cuando lo conocí, en Pueblo Chayahuita, a donde había ido a "pasear" con ocasión de una fiesta, actuaba, y era considerado por todos como un chayahuita mas.

Un segundo tipo de "nicho" ocupado por migrantes chayahuita es el de shamanes (conocidos como "brujos" en el medio mestizo, aunque la palabra tiene otra connotación en un medio nativo), viviendo en Yurimaguas y San Lorenzo. Parece, ser que aquí también tienen un relativo éxito económico ya que reclutan su clientela no sólo de otros chayahuita, sino también entre përuènante de diversos origenes y hasta entre los wiracocha.

En ambos casos, el de los mitayeros y el de los shamanes, el éxito obtenido está relacionado a la ventaja que han podido sacar de sus "calificaciones" previas como nativos tribales y del hecho de que encuentren un "mercado" urbano que "demanda" sus bienes o servicios; sean estos carne de monte o protección contra los espiritus dañinos.

D. Combinaciones de $a, b, y c$, en diferentes etapas de la historia migratoria de una misma persona o entre diferentes miembros de una familia migrante; sea en un momento dado o en generaciones sucesivas.

E. Migraciones de retorno.- Cualquiera de las estrategias anteriormente descritas puede ocasionalmente conducir a un retorno del migrante a su territorio étnico - sea a su comunidad de nacimiento u a otra - y su reinserción en su sociedad y su cultura. Esto se ve favorecido por la práctica de la matrilocalidad: una institución central en la sociedad chayahuita.

Como hemos podido encontrar en entrevistas con algunos nativos que habían hecho este paso, se puede decir que, a pesar de los azares y vicisitudes que en un momento pudieron llevarlos a abandonar su tierra, poderosos lazos afectivos se mantienen con el lugar de origen y con la propia gente. Esto se entiende, pues la identidad étnica chayahuita además de ser una "categoria de adscripción" es también una visión compartida del mundo y de la vida; un sistema de significados que le dan sentido a la existencia.

La coexistencia de sectores de población viviendo en forma "tradicional" en un territorio continuo, junto a "enclaves" nativos en áreas mestizas y junto a sectores de migrantes urbanos en diversos tipos de relación con la sociedad mayor, es una de las características distintivas de los chayahuita; como lo es el hecho de que, en general, cuando se presentan las ocasiones, representantes de estos diversos segmentos se reconocen entre sí como miembros de una misma sociedad y cultura: la de los chayahuita.

\section{Conclusiones: Definición de la identidad étnica en las sociedades amazónicas}

La identidad étnica puede definirse desde dos perspectivas complementarias. "Desde adentro", para los propios actores, compartir una misma identidad equivale a 
mantener una aptitud comunicativa (Regan 1983). Esto no sólo implica compartir un mismo idioma - lo que es en sí importante, pero no suficiente - sino también un conjunto de postulados y valoraciones comunes sobre las relaciones del hombre con el mundo y las relaciones de los hombres entre sí. "Desde fuera", las identidades étnicas son categorias de adscripción empleadas en la interacción social (Barth 1976). Desde este punto de vista, una identidad, o el grupo que la comparte, nunca se definen aisladamente, sino, implícita o explícitamente, "por oposición" frente a otras identidades o grupos con los que se mantienen relaciones.

El estudio de la etnicidad como estudio de las "fronteras" inter-étnicas es una aproximación productiva pues permite entender a los grupos étnicos a partir de sus interacciones recíprocas y no como el simple resultado de su aislamiento y hostilidad frente al mundo exterior. Sin embargo este enfoque tiene limitaciones: parte del examen de un sistema social ya constituido, analizando el papel de las categorizaciones étnicas en su funcionamiento interno, pero no examina históricamente el proceso de su constitución como sistema social.

Esto es necesario si se quiere entender la diversidad de situaciones posibles de contacto inter-étnico: complementariedad, competencia, dominación, asimilación, desplazamiento de un grupo por otro etc. En última instancia, el destino de los grupos en contacto: su persistencia o su desaparición, necesitan; para ser comprendidas, de la introducción de una "variable" histórica.

Lamentablemente este es un punto que con frecuencia ha sido ignorado para el caso de los grupos étnicos de la amazonía peruana. Tomemos, por ejemplo, la siguiente opinión:

"Desde la 'conquista espaffola', pasando por la Colonia, la época Republicana y casi hasta 10 años, la selva peruana con excepción de los grandes ríos se mantuvo altamente aislada de la vida nacional" (Uriarte, 1976, p. 14).

Investigaciones mas recientes como las de Stocks (1981), Scazzochio (1979), Fuentes (1985), Regan (1983) y otras, mucstran, para diferentes situaciones, lo insostenible de este punto de vista. Sin embargo, las implicaciones de una afirmación como la citada, me parece que hasta ahora no han sido examinadas sistemáticamente y continúan considerándose como axiomas por la mayor parte de los investigadores.

Una de estas implicaciones es la que parece esiablecer una relación de co-variación entre, por un lado, el "grado de contacto" de los grupos indígenas con la sociedad nacional, y, por otro lado, el "grado de identidad étnica". Esquematizando, tendríamos:

Grado de contacto

c. la soc. nacional

Aislados

Contacto intermitente

Contacto permanente

\section{Grado de Identidad étnica}

Fuerte

Intermedia

débil

Dejando de lado la impresición de los términos empleados (¿qué se entiende por una identidad étnica "intermedia", etc.,) creemos que el 'coeficiente de asociación' entre am- 
bas variables -en el caso de que se pudiera establecer uno lo suficientemente preciso- no mostraría una relación muy significativa y hasta podría especularse que la relación fuera, en algunos casos, de tipo negativo. La experiencia de los chayahuita, un grupo con una larga historia de contacto permanente y que mantienen una "fuerte" identidad étni$\mathrm{Ca}, \delta$, por otro lado, la de los Amarakaeri de Madre de Dios, hasta hace poco relativamente "aislados" pero con graves problemas para reproducir su sistema social, serían ejemplos en este sentido (Fuentes: 1982).

Creemos por eso que más productivo es examinar, para cada caso, el carácter que ha tenido históricamente la expansión de la economía y sociedad mayores; y cómo las demandas específicas de los diferentes modos de explotación de la mano de obra y recursos locales han tenido diferentes efectos sobre la configuración de los sistemas sociales interétnicos en la amazonía peruana. 1718

\section{NOTAS}

(1) Entre octubre de 1984 y julio de 1985 realicé una investigación en la localidad de "Pueblo Chayahuita", ubicada en el distrito de Chauapanas, provincia de Alto Amazonas, departamento de Loreto.

(2) Barth (1976) llama rasgos "diacríticos" a aquellos rasgos culturales que, a los ojos de los actores, aparecen como relevantes en la interacción, a fines de trazar las fronteras inter-étnicas.

(3) En la discusión que sigue se tiene en mente principalmente a los indígenas de la Familia lingüistica Cahuapana, aunque, en algunos aspectos, lo que aquí se dice puede aplicarse también a otros grupos.

(4) Estos movimientos fueron bastante frecuentes. Algo parecido pasó con los Muriches, parte de cuya población fué trasladada desde el bajo Paranapuras hasta el río Itaya por la década de 1920(Tessman: 1930).

(5) Hace referencia a una superestructura de relaciones de dominación de tipo personal con un fuerte contenido racista.

(6) Para 1981 Yurimaguas concentraba el $25 \%$ de la población de la extensa provincia de Alto Amazonas.

(7) Principalmente el arroz en las comunidades mas accesibles; los cerdos, aves y productos del monte en las mas distantes.

(8) La "canasta familiar" de los nativos es típica en la composición de bienes de mercado que "demandan". Alrededor de la mitad de los ingresos obtenidos por la venta de sus productos se gastan en herramientas (machetes, hachas) 6 "pertrechos" (cartuchos, pilas, pólvora, muni- 
ciones) necesarios para llevar adelante sus actividades de subsistencia (agricultura, caza y pesca). El resto se distribuye mas o menos en partes iguales en: bienes de consumo inmediato -entre los que tiene más peso la ropa y algo de menaje familiar (ollas, platos)-, gastos de transporte y ahorros pequeños (para emergencias, pago a curanderos etc).

(9) La relación con el dinero es ambigua pues, por otra parte es altamente valorado como el medio de obtener todas esas mercancías que están alli, aparentemente al alcance de la mano, pero vedadas en realidad. Al no haber acumulación, sin embargo, la monetización de la economía no se ha convertido todavía en un medio de diferenciación interna de la comunidad.

(10) Stocks distingue el tipo "colonia" o nativos "tribales" del tipo "clase" o "cholada" -esto último en la terminologia local del bajo Huallaga-, en que estos últimos son conscientes del sistema de estratificación social regional y de la posibilidad de ascender en éste a través de un abandono de la identidad étrica y de los "estigmas" a ella vinculados, como el idioma(1981).

(11) "Auca" tiene entre otros significados el de "salvaje"; también "Enemigo, adversario, rival" (Cusihuaman 1976: Diccionario Quechua, I.E.P.). Eventualmente, el temor a las incursiones aguaruna ha llevado a que los chayahuita abandonen la práctica pública del shamanismo, una institución que hasta hace poco era central en su sistema religioso.

(12) Los péwënanté ocupan los cursos inferiores de los ríos; tanto por el lado del Paranapuras como por el del Cahuapanas-Sillai, el país chayahuita, típicamente, empieza allí donde el río se angosta y las partes inundables ceden paso a terrenos en su mayor parte de "altura".

(13) Es posible que los pếwènanté se hayan conformado primeramente a partir de los grupos étnicos Muniche y Yurimaguas desestructurados como naciones indigenas pero que han mantenido rasgos separados de su cultura: notablemente aquellos directamente asociados al manejo del ecosistema local. A estos se habrian unido sumando migrantes de otras regiones de la amazonía con un "background" análogo. Tessman habia encontrado hablantes del idioma Muniche en una fecha tan reciente como 1930. Pero ya para esa época, según el mismo autor, los jóvenes estaban abandonando su lengua por el castellano. Aunque no hemos podido encontrar datos para los Yurimagras, es de suponer un proceso en el mismo sentido. A mediados del siglo pasado la hoy ciudad de Yurimaguas era todavia un pequeño caserío de indigenas de este nombre que habían adoptado el quechua (probablemente como resultado de la influencia jesuita) pero conservaban típicamente una cerámica muy fina (Raimondi, op. cit.).

(14) Para evitar confusiones se debe aclarar que en el Alto Amazonas, la categoría "mestizo" ha perdido la connotación etimológica de "transición" entre blanco e indígena para hacer referencia a una categoría étnico-cultural estable adscrita a los representantes de la sociedad nacional, independientemente del porcentaje de melanina en su piel. Stocks usa el término "blancomestizo" pero esa no es una categoria empleada por los propios actores sino que $\rightarrow$-me pareceacunada por el propio Stocks para hacer resaltar el hecho de que, aunque representantes de una cultura de orígen occidental (por ende "blanca") los peruanos somos fenotípicamente mestizos. Lo cual es un detalle que no viene al caso. De cualquier modo, la gente racialmente "blanca" no forma, como tal, parte del sistema étnico local sino que, 6 es adscrita a la no-categoria de "gringos", $\delta$, si estructuralmente tiene algo que hacer, son llamados wiracocha; por lo menos desde la perspectiva de los chayahuita.

(15) Se excluye de este análisis las migraciones al interior del propio territorio étnico: desde las zonas mas alejadas hacia aquellas ventajosamente situadas, junto a los ríos, para facilitar la comercialización de sus productos.

(16) Entre 1940 y 1983 el tamaño promedio por comunidad chayahuita ha crecido de 40.5 personas a 170. También ha crecido el número de Comunidades (Fuentes 1985).

(17) Incidentalmente, algo de esto es lo que Uriarte plantea con su caracterización de los "frentes de expansión". Sin embargo él se limita a la situación contemporánea. Habría, en todo caso, 
que proyectar el análisis diacrónicamente. Y también por cierto, dar mas precisión a las categorlas empleadas, que generalmente Uriarte define de un modo mas bien intuitivo. (Como "fagocitocis" etc).

(18) Soy deudor de Carlos Samaniego (1974) por la orientación general de este enfoque. Aunque él trata de la articulación de modos de poducción, creo que se puede extender el método de su análisis para los aspectos de las relaciones intex-étnicas. Por otra parte su caraclerización de las modalidades de expansión capitalista en América Latina no considera el área amazónica peruana. Pero su propuesta metodológica es prometedora.

\section{BIBLIOGRAFIA}

BARTH, Fredrik

1976 Los grupos étnicos y sus fronteras. FCE. México.

CABALLERO, José Marfa

1981 La Economía de la Sierra Peruana antes de la reforma agraria. IEP. Lima

CORERA, Martin

1959 En el Corazón de la Selva. Madrid

CHANTRE y Herrera, J.

1901

(1790) Historia de las misiones de la Companía de Jesús en el Marañón español.

FIGUEROA, Francisco de

1904

(1661) Relación de las Misiones de la Compañía de Jesús en el País de los Mainas. Madrid

FUENTES, Aldo

1982 Shintuya: Parentesco y relaciones de Producción en una comunidad Harakmbut de Madre de Dios. (manuscrito) CAAAP.

FUENTES, Aldo

1985 Historia, Producción, Sociedad y Ritos de los Chayahuita del Alto Amazonas. Informe de Investigación. (manuscrito) CAAAP. Lima

LATHRAP, Donald

1970 The Upper Amazon. London.

RAIMONDI, Antonio

1859 Primer viaje del Naturalista don Antonio Raimondi al departamento de Loreto, en CLLC t. VII, p. 35.

REGAN, Jaime

1983 Hacia la Tierra sin Mal. CETA. Iquitos.
SAMANIEGO, Carlos

1974 Articulaciones de Modos de Producción y Campesinados en América latina. CISE. Lima

SCAZZOCHIO, Francoise

1979 Ethnicily and Boundary maintenance among the Peruvian Forest Quechua. Tesis PH. D. Cambridge.

STOCKS, Anthony

1981 Los Nativos Invisibles. CAAAP. Lima.

TESSMAN, Gunter

1930 Die Indianer Nordost-Perus. Hamburg. (Se ha consultado una traducción manuscrita existente en el museo de la cultura peruana).

URIARTE Luis

1976 Poblaciones Nativas de la Amazonía Peruana en AP. vol 1, $\mathrm{nl}$, pp 9-58

VISALOT, Pablo

1888 Exploración de las montañas de Cahuapanas en CLLC t. III, 20-28 (1905)

WEBB, Richard

1977 Gobernment Policy and income distribution in Peru.

\section{ABREVIATURAS}

A.P. Amazonía Peruana

CLLC Colección de Leyes y documentos referentes al departamento de Loreto. Carlos Larraburre y Correa. Lima, 1905 